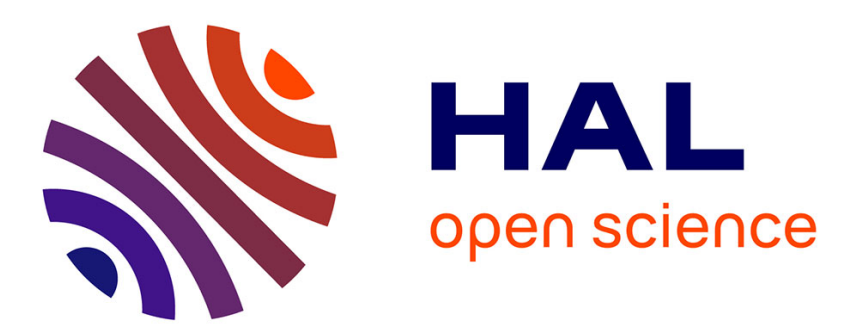

\title{
Apparatus for continuous expansion measurement and uniaxial stress application during neutron diffraction experiments
}

\author{
J.P. Bachheimer
}

\section{To cite this version:}

J.P. Bachheimer. Apparatus for continuous expansion measurement and uniaxial stress application during neutron diffraction experiments. Revue de Physique Appliquée, 1984, 19 (9), pp.739-742. 10.1051/rphysap:01984001909073900 . jpa-00245249

HAL Id: jpa-00245249

https://hal.science/jpa-00245249

Submitted on 1 Jan 1984

HAL is a multi-disciplinary open access archive for the deposit and dissemination of scientific research documents, whether they are published or not. The documents may come from teaching and research institutions in France or abroad, or from public or private research centers.
L'archive ouverte pluridisciplinaire $\mathbf{H A L}$, est destinée au dépôt et à la diffusion de documents scientifiques de niveau recherche, publiés ou non, émanant des établissements d'enseignement et de recherche français ou étrangers, des laboratoires publics ou privés. 


\title{
Apparatus for continuous expansion measurement and uniaxial stress application during neutron diffraction experiments
}

\author{
J. P. Bachheimer \\ Laboratoire de Spectrométrie Physique, B.P. 87, 38402 Saint Martin d'Hères Cedex, France
}

\begin{abstract}
Résumé. - Nous décrivons deux appareils qui ont été utilisés pour l'étude, par diffraction des neutrons, de la transition $\alpha-\beta$ du quartz $\left(573^{\circ} \mathrm{C}\right)$. Le premier est un support prévu pour être placé dans un four à vide standard de l'I.L.L. Il permet la mesure continue et simultanée $(\$ 950 \mathrm{~K})$ de la dilatation thermique du cristal dans le but d'en contrôler les gradients thermiques. Le deuxième est un appareil de compression uniaxiale (jusqu'à 1 kbar sur un échantillon de $7,5 \times 7,5 \times 30 \mathrm{~mm}^{3}$ ) qui fonctionne $(\$ 900 \mathrm{~K})$ à l'air ambiant et peut montrer aussi le gradient thermique sur l'échantillon grâce à la dilatation.
\end{abstract}

\begin{abstract}
Two devices are described which were used for the study of the $\alpha-\beta$ transition $\left(573^{\circ} \mathrm{C}\right)$ of quartz by neutron diffraction. The first one is a support designed for operation in a standard I.L.L. vacuum furnace. It enables continuous and simultaneous measurement of the thermal expansion to be made ( $\$ 950 \mathrm{~K})$ in order to control thermal gradients on the sample. The second is a uniaxial compressive stress apparatus (up to $1 \mathrm{kbar}$ on a $7.5 \times$ $7.5 \times 30 \mathrm{~mm}^{3}$ sample) which works in open air $(\$ 900 \mathrm{~K})$ and can also give an estimate of the thermal gradient from dilatation.
\end{abstract}

\section{Introduction.}

We describe two devices which were designed for studying the $\alpha-\beta$ first order transition of quartz $\left(573^{\circ} \mathrm{C}\right)$ by neutron diffraction. For the first apparatus the problem was to identify the nature of a new phase which was found by dilatometric and birefringence measurements [1] in a $1.3 \mathrm{~K}$ range around the wellknown $\alpha-\beta$ transition (Fig. 1). The thermal homogeneity of the sample appeared as a crucial parameter which could affect the meaning of the results. So to control this point and in addition to know at each temperature the phase under study, we built a special dilatometric support designed for operation in a standard I.L.L. vacuum furnace. Indeed the dilatation of quartz shows a sharp discontinuity at the transition (Fig. 1) within good temperature conditions. Thus by comparison with this "ideal » curve we can estimate the temperature gradient $\left({ }^{1}\right)$ over the whole sample and take measures to reduce it. This dilatometric support enabled us to show by means of neutrons

(1) This simple and cheap method seems more reliable for the desired accuracy of a tenth of $K$ than multiplying the number of differential thermocouples which requires very careful " in situ " calibration to determine the e.m.f. corresponding to a $0 \mathrm{~K}$ temperature difference (see for instance $[3,4])$.

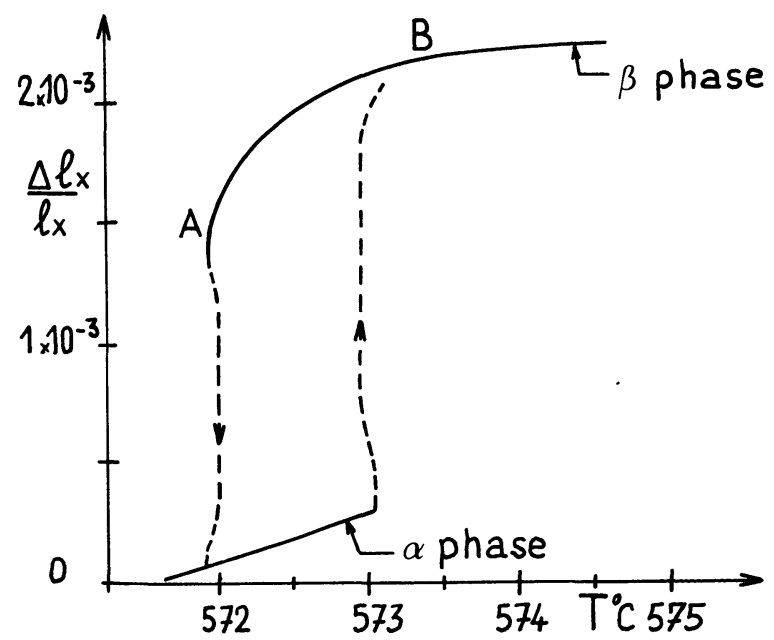

Fig. 1. - Dilatation of quartz during its first order phase transition [1]. The new phase which was to be identified by neutron diffraction is in the A-B region.

the incommensurate nature of the new phase [2] (satellite peaks around Bragg reflections) and also to study the coexistence state by controlling the position of the interface during the transition.

The second apparatus works in open air and has a rougher construction with respect to thermal gradients. 
It was designed to begin the study of the influence of a uniaxial stress (up to $1 \mathrm{kbar}$ along a $7.5 \times 7.5 \times$ $30 \mathrm{~mm}^{3}$ sample) on the incommensurate phase proved before. It includes a lever-press, plunged into a homebuilt furnace, whose deformation also gives the thermal expansion of the sample and therefore enables the thermal homogeneity in the vicinity of the transition to be estimated.

In both apparatus the sample temperature is measured with better than $0.02 \mathrm{~K}$ resolution with a $50 \Omega$ platinum sensor coupled to the sample by a metallic foil using an a.c. bridge $\left({ }^{2}\right)$. Expansion and Bragg peak neutron intensity values are recorded on a $X-Y_{1}-Y_{2}$ recorder with the temperature on the $X$ axis.

\section{Dilatometric support.}

A diagram of this set up is given in figure 2. The maximum diameter of the support is imposed by the $50 \mathrm{~mm}$ diameter port of the furnace. The useful volume of the sample 1 was chosen to be $\varnothing 12$ with $12 \mathrm{~mm}$ height. Its vertical position is imposed as shown by the figure. The platinum sensor 2 and the sample are both wrapped with a copper foil for good thermal coupling. This foil is cut in the middle to leave a passage for the neutron beam. The sample is $30 \mathrm{~mm}$ high with flat parallel ends. It is placed on parts 3 and 4 which also provide centring and temperature. The base 4 is held in position by means of three springs 5 which pull it against three silica rods 6 via Nichrome wire 7. The sample expansion is transferred outside the furnace to the L.V.D.T. transducer $12(2.5 \times$ $10^{-5} \mathrm{~mm}$ resolution) by means of three silica rods 10 and parts 8, 9 which also provide the temperature (by heat exchange with the furnace). Atmospheric pressure through welded bellows 11 provides a small force which ensures correct mechanical stability of the mechanism. Clearances at silica rod level are suppressed by folded stainless steel foil wedges. The furnace is controlled with a thermocouple (chromelalumel) 13 associated with standard I.L.L. temperature control equipment (i.e. Drusch regulator-ice point reference and magnetic amplifier to supply the niobium resistor). The long term drift as read at the sample was found to be about $0.1 \mathrm{~K} / \mathrm{K}$ ambient temperature. A differential thermocouple 14 and two extra heaters $15-15^{\prime}$ enable the vertical temperature gradient to be changed. To improve short term stability and reduce thermal inhomogeneity in the sample the support is built relatively heavy with large block surfaces in front of the inner furnace element. Shields 16 (niobium $50 \mu \mathrm{m}$ ) and 17 reduce thermal

$\left({ }^{2}\right)$ The fluctuation $(\Delta I=2 \mathrm{~A})$ of the intense $(I=100 \mathrm{~A})$ heating current of the furnace, due to regulator action, generates a low frequency modulation of the readout when we used a $51 / 2$ digital multimeter followed by a D.A. convertor.

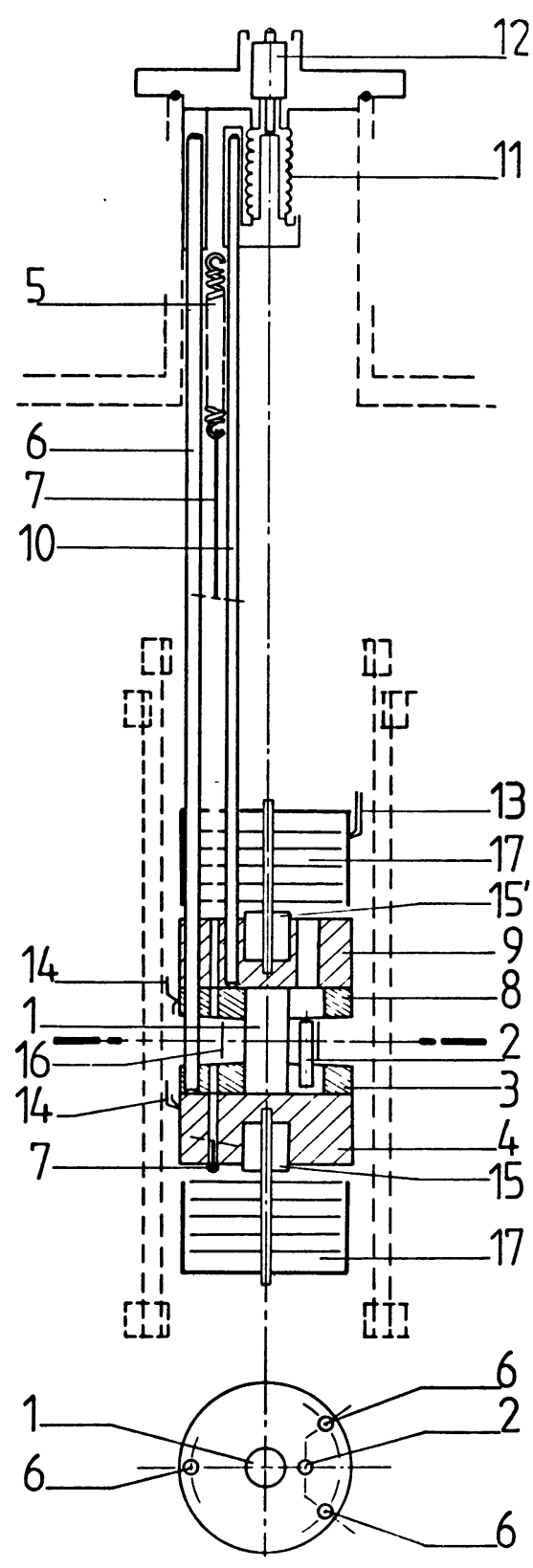

Fig. 2. - Diagram of the dilatometric support. (----) I.L.L. furnace; hatchured parts : stainless steel (310).

radiative losses around the sample and through the ends.

The thermal constant time measured at the sample is about $25^{\prime}$ at $573^{\circ} \mathrm{C}$. The work of the dilatometric support is illustrated by figures 3 and 4 . Figure 3 shows a typical sequence of gradient adjustment operations. With zero extra power the transition is spread over about $5^{\circ} .3 \mathrm{C}(3 \mathrm{a})$ with a vertical gradient of $7.5^{\circ}$ as read from the differential thermocouple. When we increase the power in 15 (a few watts) we get the hysteresis curve $b$, $c$.

By comparing with figure 1 we retain the value of $1.5^{\circ}$ for the differential thermocouple indication for the best thermal condition corresponding to a residual gradient of about $0.3^{\circ}$ on the sample. 

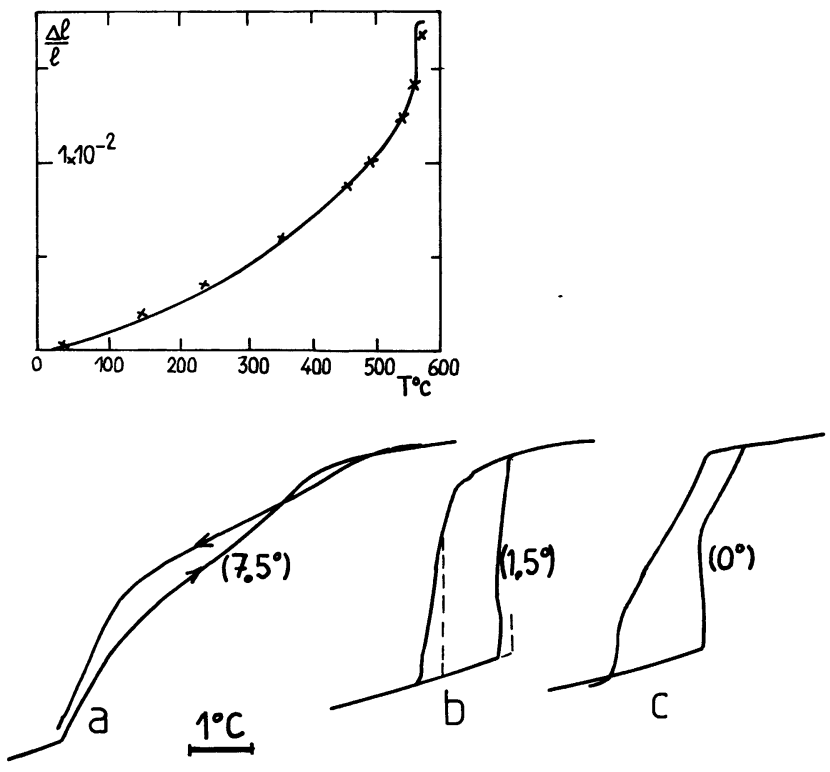

Fig. 3. - Influence of a temperature gradient on the dilatation of a $X$-quartz during the $\alpha-\beta$ transition as shown by the dilatometric support. ( ) data from the differential thermocouple. --- " ideal " curve. Insert : dilatation from the ambiant temperature to the $\beta$ phase. $\times$ Mayer (rapport C.E.A. (France) no $1330(1960))$. — rough values from dilatometric support.
Figure 4 shows how we can follow the state of the sample during a neutron experiment [5], in particular when the interfacial region progressively sweeps the central scattering volume (curve defgh). It is even possible to interrupt the cooling before completion into $\alpha$ phase and heat again (curve jklm).

\section{Compressive uniaxial stress apparatus.}

The essential features of both the lever-press and home built furnace are shown in figure 5 . The requirements were to obtain the largest solid angle possible and to put the quartz sample $1\left(7.5 \times 7.5 \times 30 \mathrm{~mm}^{3}\right)$ in horizontal position for neutron diffraction reasons. Because the thermal neutron diffusion of aluminum was found to be negligible in previous experiments we used it extensively for its high thermal conductivity. An aluminium sheet (2) $0.5 \mathrm{~mm}$ thick wraps the $50 \Omega$ sensor 3 and the sample together. The stress is applied by the action of stainless steel (310) arms 4 through axis 5 and gold foil. A notch in part 6 gives a virtual (0) elastic axis of articulation. A magnification of 12 is obtained when we applied a force $\mathbf{F}$. Thermal expansion of the sample is measured by conductive plastic linear potentiometer 7 with a magnification of fourteen. The arms are held in vertical position by the axis 8 and two ball-bearings 9 which allow the free deformation

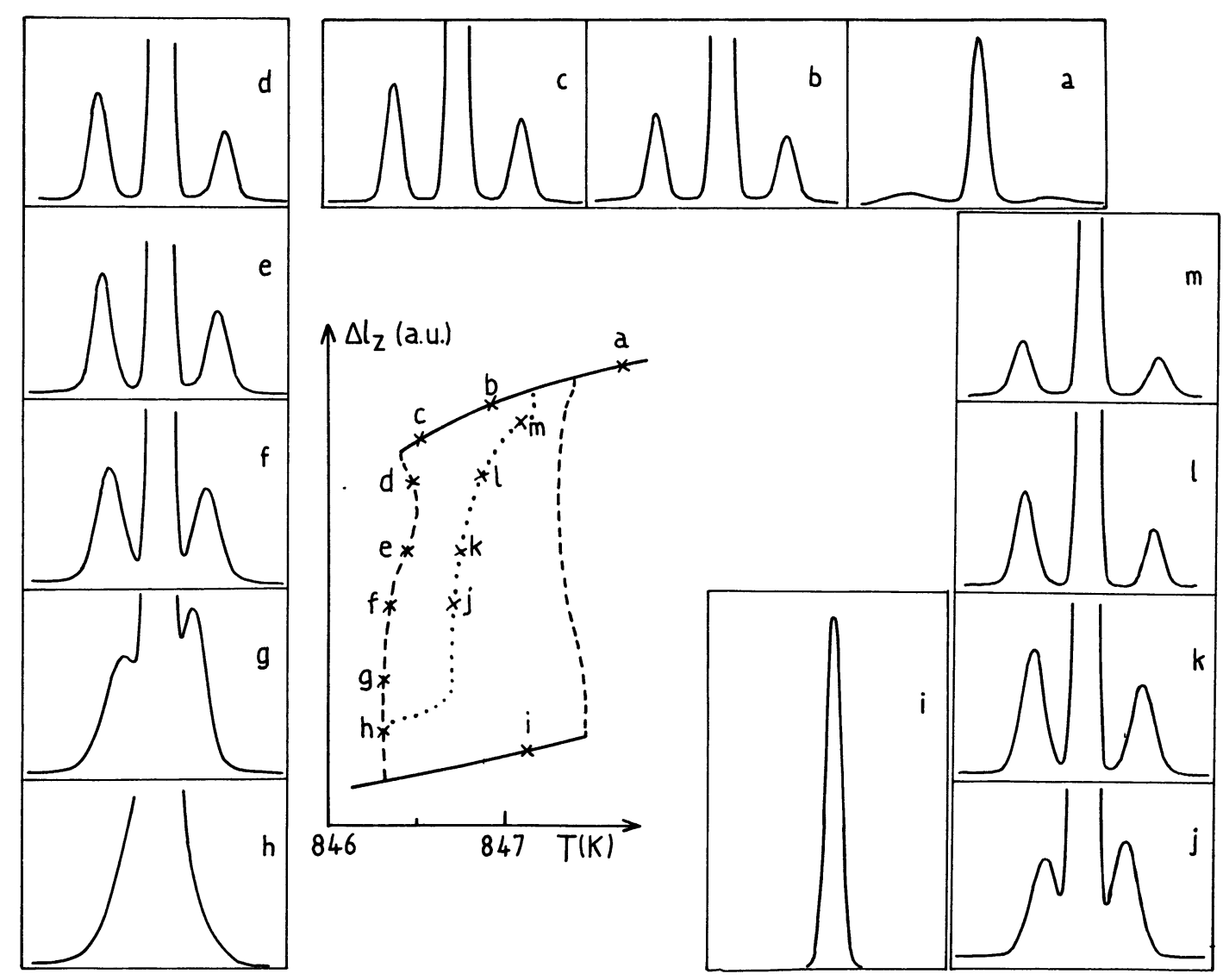

Fig. 4. - Simultaneous measurements of thermal expansion (dilatometric support) and neutron scattering. The central curve shows the dilatation of a $Z$-quartz while the surrounding curves show the shapes of the satellites (incommensurate) peaks $(\langle\zeta 30\rangle$ scans) at different stages. The full lines correspond to homogeneous phases, the dashed lines to phase coexistence (for more details see [5]). 


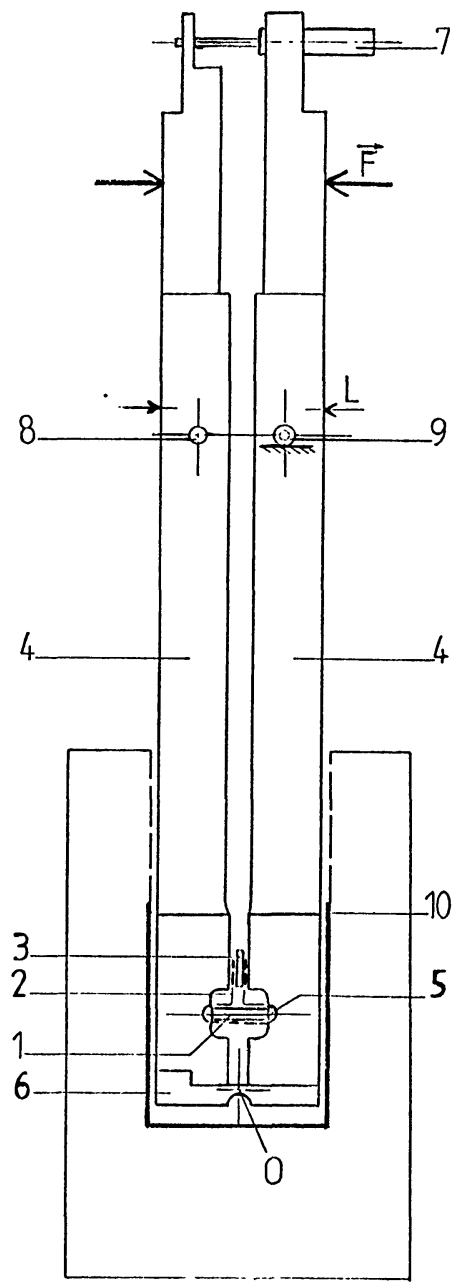

Fig. 5. - Diagram of the compressive uniaxial stress apparatus (lever-press).

of the arms $\left({ }^{3}\right)$. F was first created with a spring system but because of friction problems we found that the best way for a narrow temperature range is to fit elastic rubbers. The lever-press is heated by means of air thermal conduction and thermal radiation by the stainless steel casing 10 on which an asbestos insulated Nichrome wire is wound. Suitable windows are cut

$\left({ }^{3}\right)$ The elastic deformation of both arms is $\Delta L=2 \mathrm{~mm}$ with $F=24 \mathrm{~kg}$ at $T \sim 570^{\circ} \mathrm{C}$. out corresponding to a solid angle of $90^{\circ}$ in the horizontal plane and $60^{\circ}$ in the vertical plane. A $0.5 \mathrm{~mm}$ aluminium foil is partly screwed on arms 4 while three extra $0.5 \mathrm{~mm}$ aluminium foils act as a heat shield. The $50 \Omega$ sensor is fixed on the wall of 10 to operate the Eurotherm regulator. The regulator controls a d.c. power supply. $400 \mathrm{~W}$ is necessary to bring the sample up to $\sim 580^{\circ} \mathrm{C}$ (with a $\sim 4 \mathrm{~cm}$ thick Fiberfrax paper insulation). Figure 6 shows that a thermal inhomogeneity of about $2.8 \mathrm{~K}$ is present along the whole sample. We think we can reduce it by suitable reduction of the thermal losses around the sample.

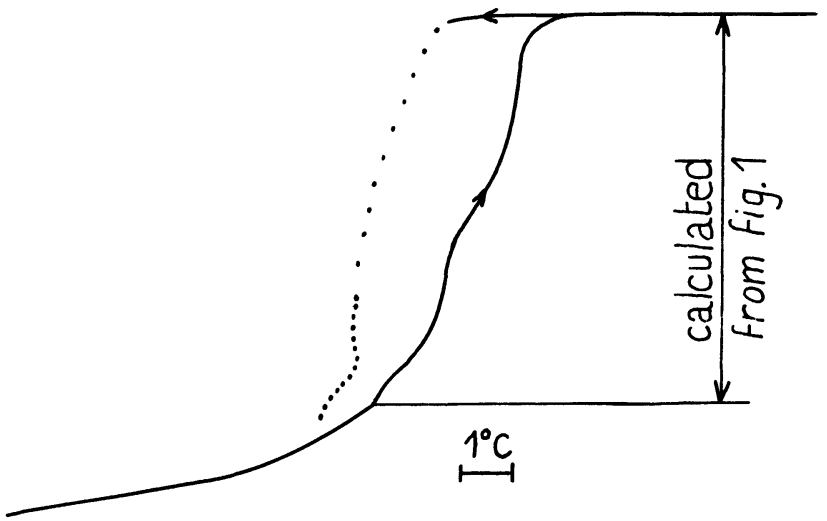

Fig. 6. - Dilatation of a $Y$-quartz during its $\alpha \rightarrow \beta$ transition as shown by the lever-press $(0.1 \mathrm{kbar}) .(\ldots)$ reconstructed from discontinuous data.

Nevertheless, with neutrons, the satellite peaks from incommensurate phase (broadened by temperature gradients) were clearly observed and their changes with temperature and stresses could be followed in three runs (0-0.23-0.7 kbar at which the sample broke) At the same time we also check the well-known $\sim 10 \% / \mathrm{kbar} \alpha-\beta$ temperature transition displacement. Thus this lever-press apparatus appears to work satisfactorily as far as the initial objective is concerned.

\section{Acknowledgments.}

The author would like to thank G. Dolino, P. Palleau, M. Vallade, R. Serve and C. Zeyen who contributed in various ways to developing these apparatus.

\section{References}

[1] Bachheimer, J. P., J. Physique Lett. 41 (1980) L-559.

[2] Dolino, G., Bachheimer, J. P., Zeyen, C. M. E., Solid State Commun. 45 (1983) 295.

[3] Ma, C. K., Ohtsuka, M., Bedford, R. E., Rev. Sci. Instrum. 51 (1980) 52.

[4] Mossman, C. A., Horton, J. L. and Anderson, R. L.,
Temperature its Measurement and Control in Science and Industry, Vol. 5 (American Institute of Physics) 1982, p. 923.

[5] Dolino, G., Bachheimer. J. P.. Berge. B., Zeyen, C. M. E., van Tendeloo, G.. Ian Landuyt, J. and Amelinckx, S., J. Physique 45 (1984) 901. 